\title{
The Effect of Processing Parameters and Calcium-stearate on the Ejection Process of Injection Molded Poly(Lactic Acid) Products
}

\author{
Tamás Tábiji,2*, Kornél Pölöskei² \\ ${ }^{1}$ MTA-BME Research Group for Composite Science and Technology, H-1111 Budapest, Muegyetem rkp. 3., Hungary \\ 2 Department of Polymer Engineering, Faculty of Mechanical Engineering, Budapest University of Technology and Economics, \\ H-1111 Budapest, Muegyetem rkp. 3., Hungary \\ * Corresponding author, e-mail: tabi@pt.bme.hu
}

Received: 22 March 2021, Accepted: 17 August 2021, Published online: 25 October 2021

\begin{abstract}
We investigated the ejection/demolding of continuous production of injection molded Poly(Lactic Acid) tensile testing specimens and analyzed the effect of $1 \mathrm{wt} \%$ Calcium-Stearate additive as demolding agent (sliding or mold release agent) on this process. We demonstrated that the Poly(Lactic Acid) specimens could get stuck in the mold or even break during demolding during continuous injection molding in a certain type of mold, which has a low draft angle and varying cavity width along the flow path. The standard dumbbell-shaped tensile testing specimen is produced in such a mold. Demolding was rated with the use of a high-speed camera into three categories (problem-free demolding / stuck, but demolded undamaged product / stuck and damaged product). Moreover, the ejector force required to push the product out of the cavity was monitored over 30 continuous injection molding cycles. We also investigated the effect of processing parameters, such as injection rate (screw speed), holding pressure, holding time, mold temperature, melt temperature, backpressure, screw rotational speed, and pre-process drying (drying or not drying the pellets before injection molding). We managed to avoid product breakage during demolding with the proper settings of certain process parameters and the use of Calcium-Stearate, an effective demolding agent. This ensured problem-free demolding and thus continuous injection molding.
\end{abstract}

Keywords

injection molding, poly(lactic acid) (PLA), ejection defect, demolding agent, processing parameters

\section{Introduction}

Nowadays, biopolymers are receiving more and more attention. They are considered the eco-friendly versions of "ordinary" plastics (crude oil-based and non-biodegradable), since biopolymers are renewable resource based (bio-based) and inherently biodegradable. These two exceptional properties allow biopolymer products to be inserted into the life cycle of nature, since $\mathrm{CO}_{2}$ from the atmosphere is bound during the production of renewable resourced used to produce biopolymers [1].

One of the most promising biopolymers is Poly(Lactic Acid) (PLA), of which around 400,000 tons are already produced globally every year. Mass production started in the 1990s, when the production of pure lactic acid through fermentation of glucose extracted from agricultural plants (maize, wheat, potato, rice, sugar beet, etc.) was industrialized. Since then, the production and the demand for PLA has been constantly expanding. It is expected that the production of PLA pellets may reach 560,000 tons/year by 2025 .

PLA can be produced by the polycondenzation of lactic acid or more likely, the polymerization of the dimer of lactic acid called lactide (the latter is a more favorable technology due to the higher achievable molecular weight). Since two stereoisomer lactic acid compounds exist, named L-lactic acid and D-lactic acid, there are a total number of three dimers named L-lactide, D-lactide and DL-lactide (meso lactide). These are typically used to produce high molecular weight PLA. Accordingly, PLA is not only one polymer, but can be considered a whole co-polymer family, where D-lactic acid and L-lactic acid co-monomer units are found in the polymer backbone. The ratio of the co-monomers, or the D-lactide content highly influences the properties of the final polymer and it is used as a material parameter that characterizes the given PLA grade in addition to molecular weight [2]. 
PLA is a linear, aliphatic, thermoplastic polyester. It has high Young's modulus ( 3.0-3.3 GPa), high strength $(\sim 60-65 \mathrm{MPa})$ but a low heat deflection temperature (around $50-55{ }^{\circ} \mathrm{C}$ ) low strain (3-5\% strain at break), low impact strength $\left(3-5 \mathrm{~kJ} / \mathrm{m}^{2}\right.$ notched Charpy impact strength) and low shrinkage (0.1-0.5\%). Its glass transition temperature is around $50-55^{\circ} \mathrm{C}$ depending on D-Lactide content and molecular weight. It has a slow crystallization rate because of its low crystallinity, which is the reason for its low HDT [2-5].

Since PLA is a thermoplastic polymer, it can be processed with wide range of thermoplastic processing technologies like injection molding, extrusion, compression molding, bottle blowing, film blowing and 3D printing (additive manufacturing). [3, 6]. Injection molding is one of the most developed thermoplastic processing technologies, where products with high dimensional accuracy are made with short cycle times with a high level of reproducibility. This is because each processing parameter, like temperature, pressure, volume, and flow rate can be precisely controlled [7]. A great deal of research has been dedicated in the last two decades to improving PLA, for example, improving its HDT through nucleation [8] or stereocomplexation [9], improving its ductility through plasticization $[10,11]$, blending $[12,13]$, orientation [14] or improving its impact strength $[15,16]$, and tensile strength through reinforcement with several types of fibers including plant [17] and basalt fibers [18, 19]. At the same time, the injection molding of PLA is little researched, especially the ejection process of PLA parts, although a continuous series production is needed, free from human intervention, for mass production.

Generally, during ejection or part removal, ejector pins push the solidified part out of the mold cavity. The main influencing factor of the ejection process determining ejection force is shrinkage and the coefficient of friction [20].

Shrinkage of the polymer part is the volume decrease due to the melt being cooled down [21]. This is an inherent feature of injection molding, meaning that shrinkage can be decreased but cannot be totally eliminated. In the case of a core-shell mold design, low shrinkage is desirable for easy demolding (avoiding shrinking onto the mold), while for cavity-like molds, high shrinkage is needed for easy demolding (inducing shrinking out of the cavity). Shrinkage is not isotropic due to the orientation and longchain molecular structure of polymers; in-flow (orientation-wise) shrinkage tends to be higher than cross-flow shrinkage [22]. Shrinkage also is affected by both processing conditions and the properties of the molded polymer [23]. Injection pressure and holding pressure directly affect the dimensions of the part through shrinkage, while melt and mold temperature affect shrinkage indirectly, since they affect melt viscosity and thus the pressure transmission ability of the melt, which influences its ability to replicate the topography of the mold. Each given polymer has its own basic viscosity and shrinkage properties, which are dependent on molecular weight, additive content (sliding agents, fillers and reinforcements affect viscosity) or crystalline structure (amorphous or semi-crystalline). Semi-crystalline polymers tend to have higher shrinkage than amorphous polymers.

The other main factor that influences ejection is the coefficient of friction, which determines the forces that develop between the polymer surface and the mold surface, originating from the shrinkage of the polymer part onto the mold. Friction is composed of three mechanisms [24]:

1. asperity deformation,

2. ploughing of the interface,

3. and adhesion.

Asperity and ploughing are related to dynamic friction, while adhesion is related to static friction. If the surfaces are theoretically perfectly smooth $\left(\mathrm{R}_{\mathrm{a}}\right.$ surface roughness is considered as zero) only adhesion remains, which could develop even between the steel or aluminum of the mold and the polymer product during solidification, if some chemical affinity is present $[25,26]$. This adhesion has to be overcome during the ejection of the polymer part by the force transmitted by the ejector pins. After that, dynamic friction can still play a role since the edges of the polymer part will still be in kinetic frictional contact with the steel cavity, along the thickness of the part if the mold was designed with a low draft angle. Additionally, friction is affected by mold properties as well, which include mold material (steel or additive manufactured epoxybased polymer) or mold design like surface finish (surface roughness), draft angle, as well as the number and location of ejector pins. Since the polymer melt tends to replicate mold texture, increasing roughness complicates ejection, while increasing draft angle makes ejection easier. In the plastic industry, demolding agents, or sliding or mold release agents in other words, like magnesium-stearate, calcium-stearate or lithium-stearate are usually used to decrease the coefficient of friction (and thus wear) as 
well as melt viscosity, and thus to ensure easier demolding, since the demolding agents, as low molecular weight materials, migrate to the surface of the polymer [27].

Nevertheless, if the ejection process is in any way disturbed, continuous production may stop, which results in high additional production costs. This can be caused by the part sticking on the wrong mold half (stationary), which is in most cases, the result of bad main ejector pin design (need for undercutting). Another problem - which is the main focus of this paper - is that even when the part stays in the moveable mold half, where it should, when the ejector pins start moving forward, the part may get stuck because its movement is not perfectly aligned, parallel movement. This could happen in cavity-like molds with varying cavity width along the flow path, since in-flow shrinkage may develop tension on the wall of the mold cavity in parts with varying cavity width, causing the product to get stuck. Such a mold is the mold for the ISO standard dumbbell-shaped ("dog bone") tensile specimen [28], where the $20 \mathrm{~mm}$ width narrows to $10 \mathrm{~mm}$ and widens up again to $20 \mathrm{~mm}$ along the flow path.

Since PLA generally has very low shrinkage, around $0.1-0.3 \%$, and high modulus and weak impact properties, demolding PLA products is difficult [3, 29]. Moreover, the ejection of PLA products injection molded into molds designed with varying cavity width along the flow path can also go wrong due to the tendency of PLA to stick into the mold. This can even lead to part breakage during ejection and the interruption of series production. We demonstrated this type of ejection defect during the series production of injection molded PLA tensile specimens, and investigated how ejection is affected by the processing parameters. Finally, we examined how a demolding agent affects this ejection defect and the properties of PLA. Although demolding agents are often used in the series injection molding of plastics, we have not found a single paper in the literature focusing on the injection molding of demolding agent-filled PLA.

\section{Experimental}

We used 3100HP PLLA from NatureWorks (USA). The PLA had a density of $1.24 \mathrm{~g} / \mathrm{cm}^{3}$, a glass transition temperature of $50{ }^{\circ} \mathrm{C}$, a crystal melting range of $165-180{ }^{\circ} \mathrm{C}$, a Melt Flow Index (MFI) of $24 \mathrm{~g} / 10 \mathrm{~min}$ (at $210{ }^{\circ} \mathrm{C}, 2.16 \mathrm{~kg}$ ) and a molding linear shrinkage of $0.2-0.4 \%$. The demolding agent calcium-stearate (Ca-ST) was supplied by Molar Chemicals Ltd. (Hungary). Prior to processing, we dried the PLA in a hot air dryer at $85{ }^{\circ} \mathrm{C}$ for 8 hours to remove residual moisture, which could induce hydrolysis during processing.
A twin-screw extruder type LabTech LTE 26-44 was used equipped with a $26 \mathrm{~mm}$ diameter screw and an L/D ratio of 44 to add $1 \mathrm{wt} \% \mathrm{Ca}-\mathrm{ST}$ to PLA and compound them. The temperatures of the barrel temperature zones were $190-185-180-175-170{ }^{\circ} \mathrm{C}$ (from die to hopper), and screw rotation rate was $101 / \mathrm{min}$. The extrudate was pelletized and re-dried (crystallized) at $85^{\circ} \mathrm{C}$ for 8 hours prior to further processing. MFI was measured for both neat PLA, extruded pure PLA (so that they had the same thermal history as Ca-ST filled PLA) and Ca-ST filled PLA at $190^{\circ} \mathrm{C}$ and a load of $2.16 \mathrm{~kg}$. Then ISO 527-2/1A standard [28] tensile test specimens were injection molded (Fig. 1).

This type of mold was chosen since it has a mold cavity design with varying widths along the flow path, which could be problematic, as discussed in the introduction.

The following method was used:

- Initial cleaning of the mold cavity with acetone and spraying it with a mold release spray (type Lusin Alro LL 261) before starting series production,

- Starting continuous injection molding with a certain set of processing parameters,

- Monitoring the force required by the ejector pins to push the product from the mold cavity in each cycle,

- Rating the nature of demolding in each cycle (problem-free demolding / stuck, but demolded undamaged product / stuck and damaged product), with a high-speed camera (Keyence VW-9000),

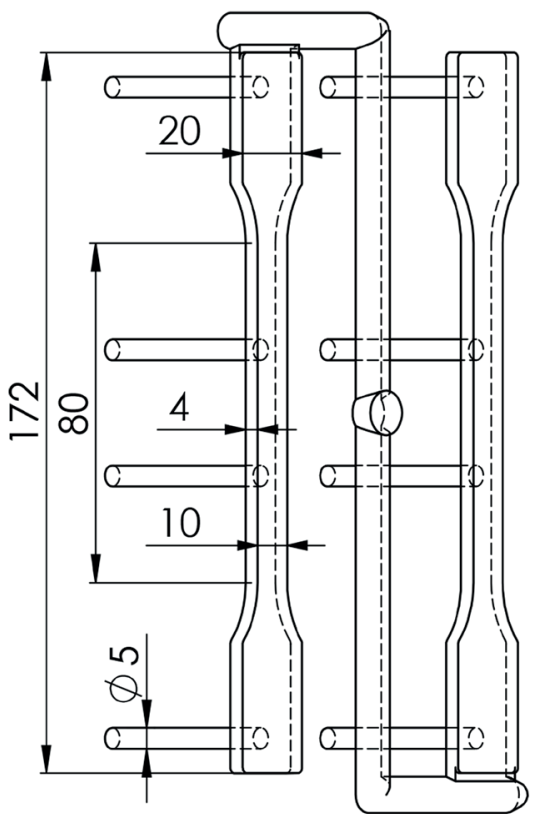

Fig. 1 Dimensions of ISO 527-2/1A standard tensile test specimen indicating the location of the ejector pins [28] 
- Monitoring injection pressure and measuring specimen length for the calculation of shrinkage and mass for volume fill analysis.

After 30 cycles, series production was stopped, a new set of processing parameters were set, the mold cavity was cleaned with acetone and sprayed again with mold release spray and the process was started again. Both pure PLA and CaST filled PLA were investigated as well as injection rate (screw speed) $\left(10-90 \mathrm{~cm}^{3} / \mathrm{s}\right)$, holding pressure (25-800 bar), holding time (10-30 s), mold temperature $\left(20-40^{\circ} \mathrm{C}\right)$, melt temperature $\left(190-210^{\circ} \mathrm{C}\right)$, backpressure (10-50 bar), screw rotational speed $(5-30 \mathrm{~m} / \mathrm{min})$, and pre-process drying (yes/no). The specimens were injection molded with an Arburg Allrounder Advance 270S 400-170 injection molding machine with $30 \mathrm{~mm}$ diameter screw. The basic setup was the following: $25^{\circ} \mathrm{C}$ mold temperature, 190-185-180-175-170 ${ }^{\circ} \mathrm{C}$ barrel temperature zones (from nozzle to hopper), $50 \mathrm{~cm}^{3} / \mathrm{s}$ injection rate, 600 bar holding pressure, $20 \mathrm{~s}$ holding time, $15 \mathrm{~m} / \mathrm{min}$ screw rotational speed, 30 bar backpressure and $30 \mathrm{~mm} / \mathrm{s}$ ejector pin speed.

We also examined the properties of the pure PLA and Ca-ST filled PLA specimens (produced only using the basic injection molding parameter setup) by Differential Scanning Calorimetry (DSC), tensile testing and Charpy impact testing. DSC was performed with a TA Instruments Q2000 calorimeter. 4-6 mg samples were tested with nitrogen as purge gas at $50 \mathrm{ml} / \mathrm{min}$. In non-isothermal mode from $0{ }^{\circ} \mathrm{C}$ to $200{ }^{\circ} \mathrm{C}$ and with a heating and cooling rate of $5{ }^{\circ} \mathrm{C} / \mathrm{min}$, we determined the glass transition temperature $\left(\mathrm{T}_{\mathrm{g}}\right)$, the cold crystallization temperature $\left(\mathrm{T}_{\mathrm{cc}}\right)$, the enthalpy of cold crystallization $\left(\Delta \mathrm{H}_{\mathrm{cc}}\right)$, the melting temperature $\left(\mathrm{T}_{\mathrm{m}}\right)$, and the enthalpy of fusion $\left(\Delta \mathrm{H}_{\mathrm{m}}\right)$ of the samples from the heating scan, and the crystallization temperature $\left(T_{c}\right)$, and enthalpy of crystallization $\left(\Delta \mathrm{H}_{\mathrm{c}}\right)$ from the cooling scan. Crystallinity was calculated from the first heating scan of the injection molded specimens with Eq. (1):

$$
\mathrm{X}=\frac{\Delta \mathrm{H}_{\mathrm{m}}-\Delta \mathrm{H}_{\mathrm{cc}}}{\Delta \mathrm{H}_{\mathrm{f}}} \cdot 100[\%],
$$

where $\mathrm{X}[\%]$ is the calculated crystallinity, $\Delta \mathrm{H}_{\mathrm{m}}[\mathrm{J} / \mathrm{g}]$ and $\Delta \mathrm{H}_{\mathrm{cc}}[\mathrm{J} / \mathrm{g}]$ are the enthalpy of fusion and the enthalpy of cold crystallization, respectively, while $\Delta \mathrm{H}_{\mathrm{f}}[\mathrm{J} / \mathrm{g}]$ is the enthalpy of fusion for $100 \%$ crystalline PLA ( $93.0 \mathrm{~J} / \mathrm{g}$ ) [30]. Tensile tests were performed with a Zwick Z020 universal tensile testing machine equipped with a Zwick BZ 020/TN2S force measuring cell with a force limit of $20 \mathrm{kN}$. Crosshead speed was $5 \mathrm{~mm} / \mathrm{min}$, and initial cross head distance was
$115 \mathrm{~mm}$. The Charpy impact tests were performed on $2 \mathrm{~mm}$ deep "V" notched samples with a Ceast Resil Impactor impact testing machine equipped with a $2 \mathrm{~J}$ impact energy hammer and a DAS8000 data collector unit. In both tests, 6 specimens each were tested at room temperature. The heat deflection temperature was measured with a Ceast HV3 type HDT equipment, according to the ISO 75-1:2020 standard [31]. HDT B type tests were carried out in flatwise mode with a loading stress of $0.45 \mathrm{MPa}$, a heating rate of $2{ }^{\circ} \mathrm{C} / \mathrm{min}\left(120^{\circ} \mathrm{C} /\right.$ hour $)$ and a span length of $64 \mathrm{~mm} .3$ parallel specimens were investigates.

\section{Results and discussion}

First, the MFI of pure PLA, extruded PLA (with the same thermal history as compounded PLA) and compounded PLA with $1 \mathrm{wt} \% \mathrm{Ca}$-ST was measured. The MFI of pure PLA, extruded PLA and Ca-ST filled PLA were $9.6 \pm 1.2 \mathrm{~g} / 10 \mathrm{~min}$, $13.7 \pm 0.8 \mathrm{~g} / 10 \mathrm{~min}$ and $25.3 \pm 1.8 \mathrm{~g} / 10 \mathrm{~min}$, respectively. It is evident that extrusion slightly increased the MFI of pure PLA, which is the sign of a minor molecular weight loss during processing, while Ca-ST filled PLA had the highest MFI, as Ca-ST improves sliding and decreases viscosity. Using $1 \mathrm{wt} \%$ of Ca-ST almost doubled the MFI value of extruded PLA. Both PLA and Ca-ST filled PLA were injection molded into tensile specimens and DSC scans were performed to determine the effect of Ca-ST on PLA (Fig. 2).

For pure PLA, $\mathrm{T}_{\mathrm{g}}, \mathrm{T}_{\mathrm{cc}}, \mathrm{T}_{\mathrm{m}}$ and $\mathrm{T}_{\mathrm{c}}$ were found to be $56.0^{\circ} \mathrm{C}$, $94.8^{\circ} \mathrm{C}, 176.0^{\circ} \mathrm{C}$ and $105.3{ }^{\circ} \mathrm{C}$, respectively. In the case of Ca-ST filled PLA, there was no change in $\mathrm{T}_{\mathrm{g}}$, but $\mathrm{T}_{\mathrm{cc}}$ decreased by $7.8^{\circ} \mathrm{C}$ and $\mathrm{T}_{\mathrm{c}}$ increased by $3.3^{\circ} \mathrm{C}$, which indicates an increased crystallization rate due to the increased molecular chain mobility that the Ca-ST induced. This means that $\mathrm{Ca}-\mathrm{ST}$ had a slight nucleation effect on PLA. Accordingly, the crystallinity of pure PLA molded specimens was found to be $21.3 \%$, while the Ca-ST filled PLA molded specimen had a slightly increased crystallinity of $23.4 \%$. The difference is practically minor, due to the fact that even though $\mathrm{Ca}-\mathrm{ST}$ enhanced the crystallization rate of PLA, during processing, a $15-30{ }^{\circ} \mathrm{C}$ cold mold is generally used (to quickly cool the product below $\mathrm{T}_{\mathrm{g}}$ ), which retards crystallization. In the next step, we injection molded pure PLA and Ca-ST filled PLA into the tensile specimen mold, to qualify the ejection process and determine the ejector force required for demolding (Fig. 3).

After the initial ejector force value of $0.6 \mathrm{kN}$, it monotonously increased up to the $2.6-2.8 \mathrm{kN}$ range, due to the gradually vanishing mold release spray from cycle to cycle. During these 20 investigated cycles, the quality of 


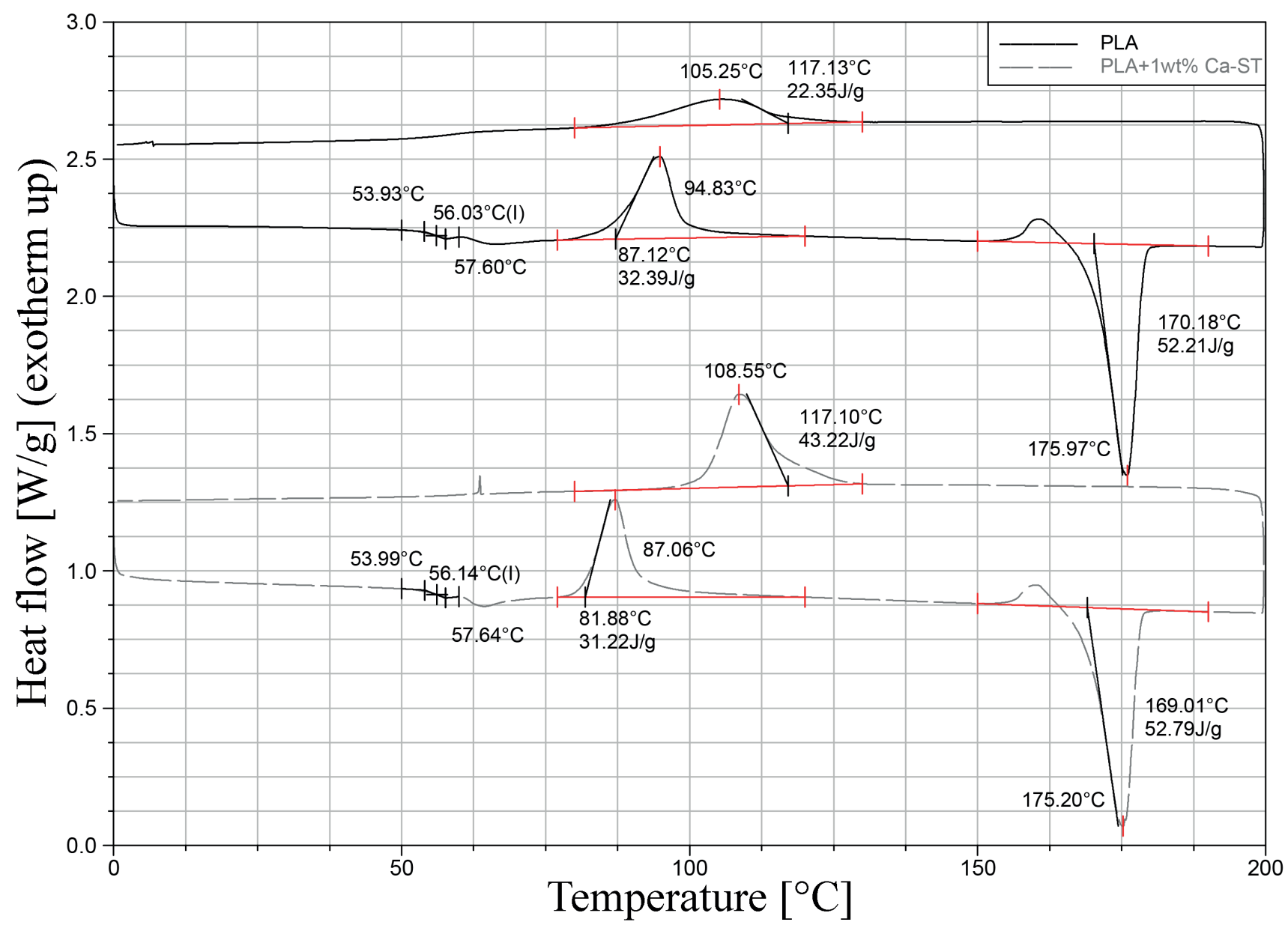

Fig. 2 Heating and cooling DSC scans of pure and Ca-ST filled PLA

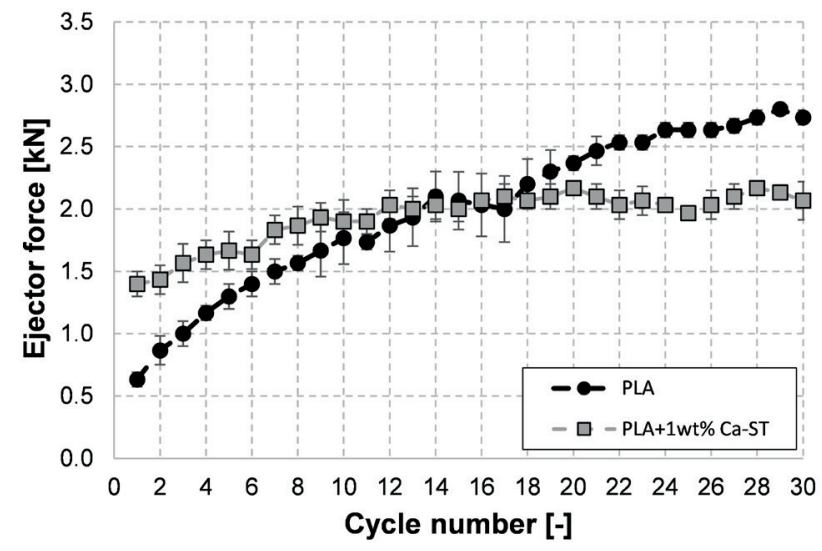

Fig. 3 Ejector force as a function of cycle number for PLA and Ca-ST filled PLA. Product breakage occurs above the cycle number of 14 for PLA, while there was no product breakage with Ca-ST filled PLA

demolding changed from perfect demolding (cycles 1-5) to the second stage, when the product stuck into the mold but was demolded undamaged (cycles 6-12) and finally to the third stage, when the product stuck into the mold and was eventually broken during demolding (cycles 13-20).
The product stuck into the mold at two critical locations, where cavity width changed along the flow path from 20 $\mathrm{mm}$ to $10 \mathrm{~mm}$, and from $10 \mathrm{~mm}$ to $20 \mathrm{~mm}$ (Fig. 4).

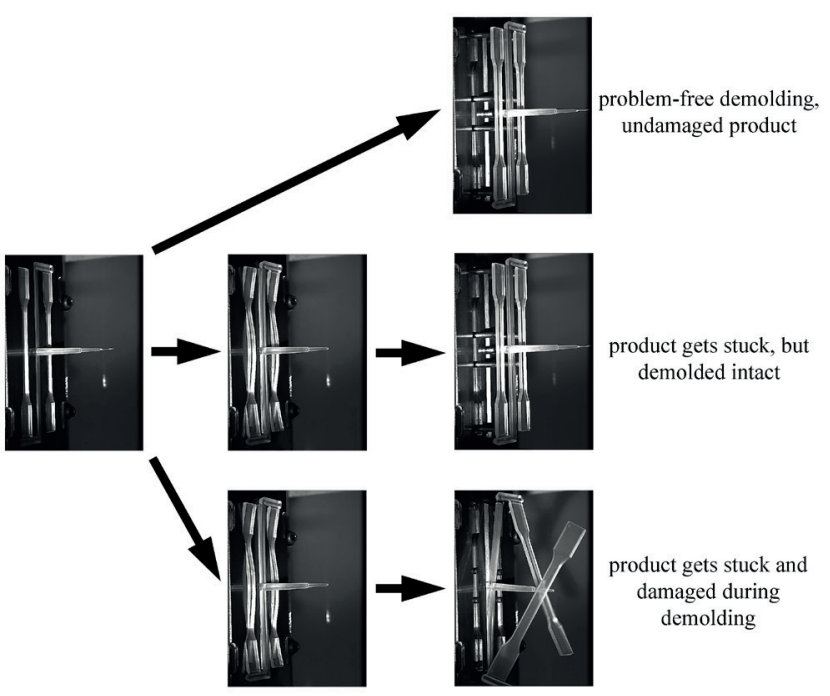

Fig. 4 The ejection process and its three outcomes: problem-free demolding (undamaged product) / stuck, but demolded, undamaged product / stuck and damaged (broken) product 
The reason for this kind of behaviour during ejection is that in such molds, a tension develops in the solidified product against the parts of the steel cavity where cavity width changes along the flow path (Fig. 5). This ejection defect can be decreased if the ejector pins are positioned at the points where cavity width changes.

Additionally, the sticking of PLA to the steel mold can also be due to a potential chemical affinity between lactic acid (either the monomer content of PLA or which develops during processing) and the $\mathrm{Fe}_{2} \mathrm{O}_{3}$ oxide layer of the steel mold. Moreover, lactic acid may also corrode or even dissolve steel, which increases surface roughness.

When PLA was filled with Ca-ST, the initial ejector force was higher $(1.4 \mathrm{kN})$ than in the case of pure PLA. This may be related to the decreased viscosity and thus the higher level of filling of the mold cavity at the same holding pressure. This is represented by the mass of the specimens, since the mass of the specimens made from pure PLA was $11.93 \pm 0.02 \mathrm{~g}$, while the mass of the specimens made from Ca-ST filled PLA increased to $11.97 \pm 0.03 \mathrm{~g}$. Also, the injection molding of Ca-ST filled PLA resulted in undamaged products with much lower tendency to get stuck into the mold, which was shown by the ejector force, which levelled off at lower value $(2.1 \mathrm{kN})$. Also, no specimens broke during demolding.

Then, we analyzed the effect of injection molding processing parameters (Figs. 6 and 7). We only highlighted the curve of those processing parameters which had a significant effect on the ejector force.

As can be observed, low injection rate, low holding pressure, low holding time and low screw rotational speed decreased ejector force and thus eased demolding, while high holding pressure, and high mold and melt temperatures and using undried pellets made demolding more problematic. On the contrary, back pressure had no significant effect on the quality of demolding. All the above-mentioned

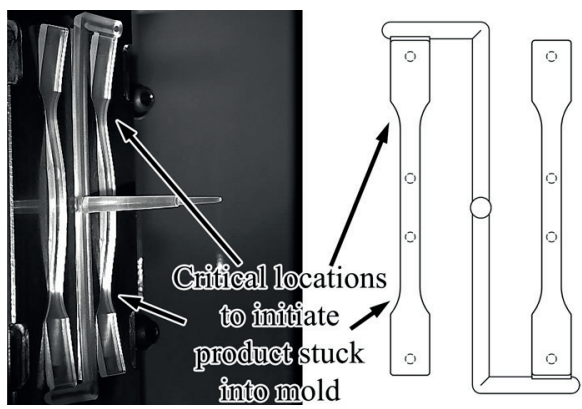

Fig. 5 The product stuck into the mold and the critical locations in the mold cavity where this phenomenon is initiated

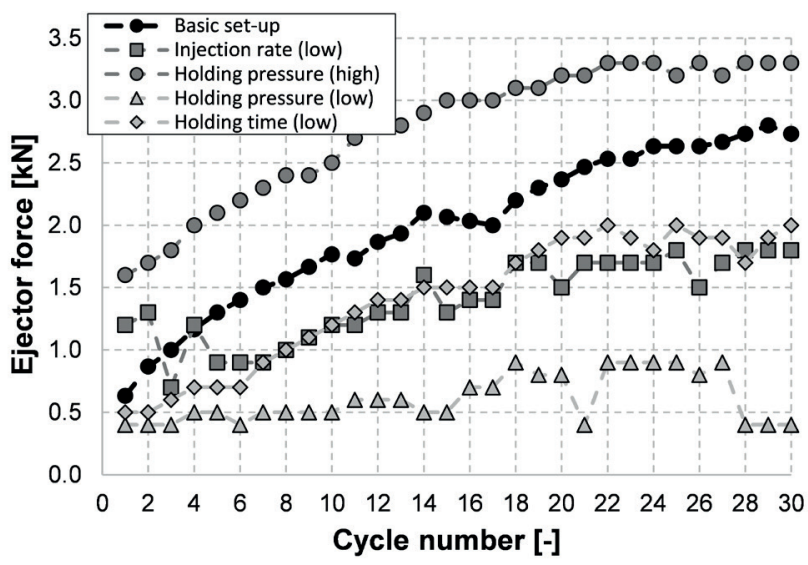

Fig. 6 The Effect of injection rate $\left(10 \mathrm{~cm}^{3} / \mathrm{s}\right)$, holding pressure $(25$ and 800 bar) and holding time (10 s) on ejector force. Product breakage occurred above cycle number 14 (basic setup), 13 (low injection rate) and 15 (high holding pressure), while there was no product breakage when low holding pressure or low holding time was used. Maximum standard deviation was $0.3 \mathrm{kN}$

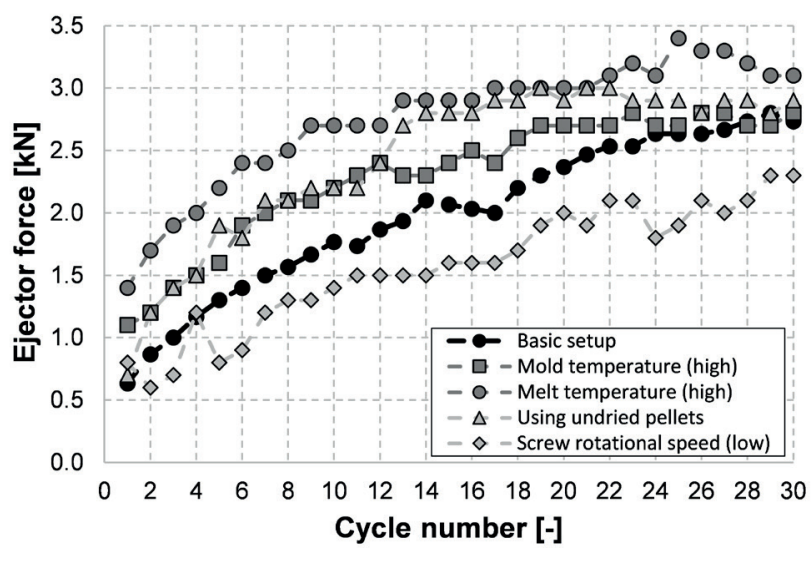

Fig. 7 The effect of mold temperature $\left(40^{\circ} \mathrm{C}\right)$, melt temperature $\left(230^{\circ} \mathrm{C}\right)$, screw rotational speed $(5 \mathrm{~m} / \mathrm{min})$, and using undried pellets on the ejector force. Product breakage occurs above cycle number 14 (basic setup), 19 (high mold temperature), 12 (high melt temperature), 24 (low screw rotational speed) and 8 (undried pellets). Maximum standard deviation was $0.3 \mathrm{kN}$

parameters affected products mass (due to the level of mold cavity filling) and product length (due to shrinkage) and a direct correlation could be found between ejector force and the above-mentioned two product characteristics (Fig. 8).

Since high holding pressure as well as high mold and melt temperature were the processing parameters that increased ejector force and the tendency for the specimen to get stuck into the mold and break during demolding, the effect of Ca-ST was investigated with the use of these processing parameters (Fig. 9).

As can be seen, Ca-ST was effective in decreasing ejector force (and thus easing demolding) in the case of high mold and melt temperatures, but it increased ejector 


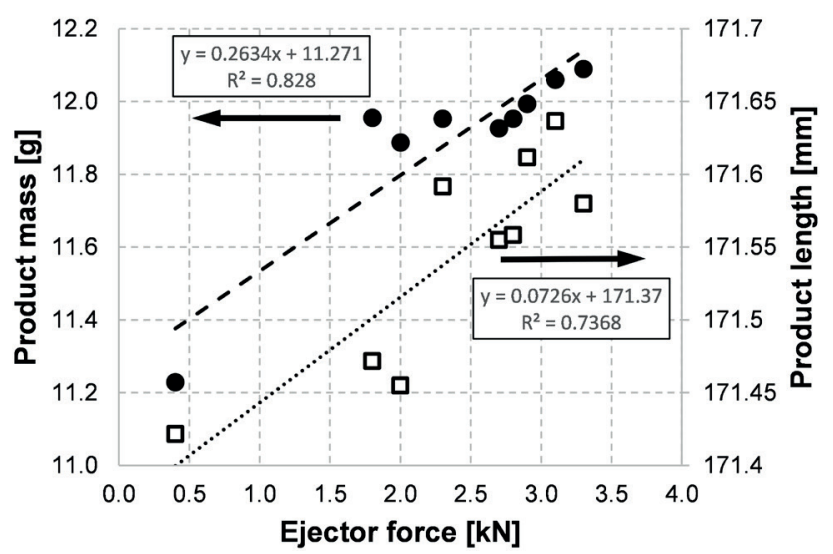

Fig. 8 Correlation between product mass/product length and ejector force

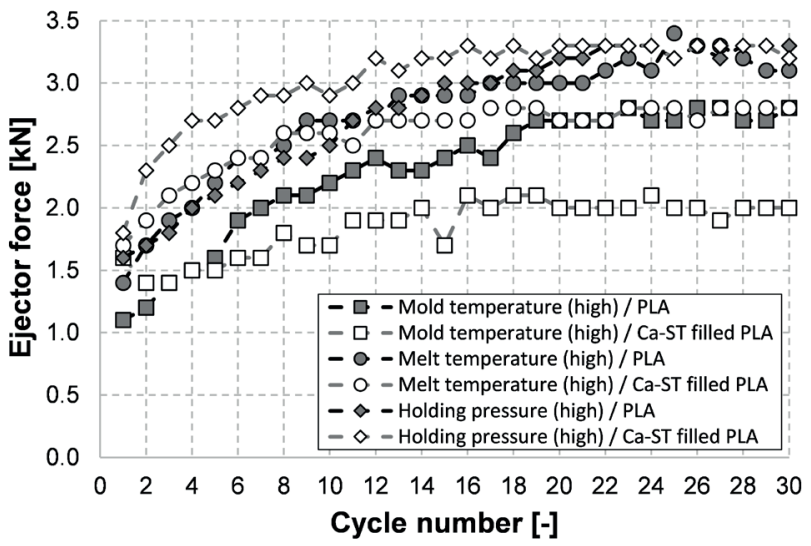

Fig. 9 The effect of mold temperature $\left(40^{\circ} \mathrm{C}\right)$, melt temperature $\left(230^{\circ} \mathrm{C}\right)$ and holding pressure ( 800 bar) on the ejector force for pure and Ca-ST filled PLA. Product breakage occurs above cycle number 19 (high mold temperature), 12 (high melt temperature) and 15 (high holding pressure), while there was no product breakage when using Ca-ST filled PLA with either processing parameter. Maximum standard deviation was $0.3 \mathrm{kN}$

force when high holding pressure was applied. The latter could be explained by the fact that Ca-ST decreased viscosity and thus high holding pressure increased the level of mold cavity filling and thus product mass even more. Nevertheless, in all these cases, the breakage of injection molded products could be fully avoided by using $\mathrm{Ca}-\mathrm{ST}$, while without using $\mathrm{Ca}-\mathrm{ST}$ and careful attention to the above-mentioned processing parameters, specimens broke 12-19 cycles after starting continuous production.

Finally, we investigated the mechanical properties and HDT of pure PLA and Ca-ST filled PLA (Table 1).

Ca-ST had a minor embrittlement effect, decreasing strength, elongation, work of fracture and impact strength, thus although it had a positive effect on demolding, it is not recommended to use in PLA in higher amounts.
Table 1 Mechanical properties and HDT of pure and Ca-ST filled PLA

\begin{tabular}{lcc}
\hline Property & PLA & Ca-ST filled PLA \\
\hline Tensile strength [MPa] & $66.7 \pm 1.8$ & $62.5 \pm 1.6$ \\
Tensile modulus [MPa] & $3420 \pm 18$ & $3410 \pm 25$ \\
Elongation at break [\%] & $3.5 \pm 0.6$ & $2.7 \pm 0.4$ \\
Work of fracture [J] & $7.3 \pm 1.1$ & $4.8 \pm 0.9$ \\
$\begin{array}{l}\text { Charpy impact strength } \\
\text { (notched) }\left[\mathrm{kJ} / \mathrm{m}^{2}\right]\end{array}$ & $3.1 \pm 0.5$ & $2.2 \pm 0.6$ \\
Heat deflection temperature $\left[{ }^{\circ} \mathrm{C}\right]$ & $54.4 \pm 0.4$ & $53.6 \pm 0.3$ \\
\hline
\end{tabular}

\section{Conclusion}

We investigated the ejection process of continuous production of injection molded Poly(Lactic Acid) (PLA) tensile specimens. We analyzed the effect of processing parameters, as well as the effect of the demolding agent Calcium-Stearate (Ca-ST). We found that injection molded ISO 527-2/1A standard [28] PLA tensile test specimens may get stuck or even break during demolding, since this mold design has varying cavity width along the flow path. Accordingly, tension on the wall of the mold cavity may develop where cavity width changes, causing the product to get stuck. Moreover, there might also be chemical affinity between lactic acid and the $\mathrm{Fe}_{2} \mathrm{O}_{3}$ oxide layer of the steel mold, and lactic acid may corrode or dissolve steel in the long term, which increases surface roughness. All these factors promote the sticking of PLA to steel molds. We demonstrated that for pure PLA specimens, the ejector force monotonously increased from cycle to cycle (after initial cleaning and spraying the mold with mold release) and the quality of demolding changed from undamaged product to stuck and damaged (broken) product. Ca-ST prevented this and resulted in undamaged products with much lower tendency to get stuck into the mold, which was represented by reduced ejector force. We also investigated the effect of processing parameters and found that high holding pressure as well as high mold and melt temperature increase the tendency for PLA products to get stuck into the mold, while Ca-ST was again found effective and undamaged products were injection molded even with these processing setups. We also found that $1 \mathrm{wt} \%$ Ca-ST had a minor nucleating effect $(+2.1 \%$ crystallinity), but it also had some embrittlement effect on PLA. Finally, we demonstrated that $\mathrm{Ca}-\mathrm{ST}$ could be effectively used as a demolding (mold release) agent to achieve continuous injection molding series production of PLA products, 
while the chemical effect of lactic acid on the steel mold still has to be investigated.

\section{Acknowledgements}

This work was supported by the National Research, Development, and Innovation Office, Hungary (2019-1.1.1PIACI-KFI-2019-00205, 2019-1.1.1-PIACI-KFI-2019-00335, 2017-2.3.7-TÉT-IN-2017-00049, OTKA FK134336). The research reported in this paper and carried out at BME has been supported by the NRDI Fund (TKP2020 NC, Grant No. BME-NCS) based on the charter of bolster issued by

\section{References}

[1] Flieger, M., Kantorová, M., Prell, A., Řezanka, T., Votruba J. "Biodegradable plastics from renewable resources", Folia Microbiolologica, 48(1), Article number: 27, 2003. https://doi.org/10.1007/BF02931273

[2] Auras, R. A., Lim, L. T., Selke, S. E. M., Tsuji, H. (eds.) "Poly(Lactic Acid) Synthesis, Structures, Properties, Processing and Applications", John Wiley and Sons, Hoboken, NJ, USA, 2010.

[3] Lim, L. T., Auras, R., Rubino, M. "Processing technologies for poly(lactic acid)", Progress in Polymer Science, 33(8), pp. 820-852, 2008.

https://doi.org/10.1016/j.progpolymsci.2008.05.004

[4] Tábi, T., Hajba, S., Kovács, J. G. "Effect of crystalline forms ( $\alpha$ ' and $\alpha)$ of poly(lactic acid) on its mechanical, thermo-mechanical, heat deflection temperature and creep properties", European Polymer Journal, 82, pp. 232-243, 2016.

https://doi.org/10.1016/j.eurpolymj.2016.07.024

[5] Tábi, T., Wacha, A. F., Hajba, S. "Effect of D-Lactide content of annealed poly(lactic acid) on its thermal, mechanical, heat deflection temperature, and creep properties", Journal of Applied Polymer Science, 136(8), Article number: 47103, 2019. https://doi.org/10.1002/app.47103

[6] Hanon, M. M., Marczis, R., Zsidai, L. "Influence of the 3D Printing Process Settings on Tensile Strength of PLA and HT-PLA", Periodica Polytechnica Mechanical Engineering, 65(1), pp. 38-46, 2021. https://doi.org/10.3311/PPme.13683

[7] Sin, L. T., Tueen, B. S. "10 - Injection Molding and ThreeDimensional Printing of Poly(Lactic Acid)", In: Polylactic Acid: A Practical Guide for the Processing, Manufacturing, and Applications of PLA, William Andrew Publishing, Norwich, NY, USA, pp. 325-345, 2019.

https://doi.org/10.1016/B978-0-12-814472-5.00010-8

[8] Schäfer, H., Pretschuh, C., Brüggemann, O. "Reduction of cycle times in injection molding of PLA through bio-based nucleating agents", European Polymer Journal, 115, pp. 6-11, 2019. https://doi.org/10.1016/j.eurpolymj.2019.03.011

[9] Srithep, Y., Pholharn, D., Turng, L. S., Veang-in, O. "Injection molding and characterization of polylactide stereocomplex", Polymer Degradation and Stability, 120, pp. 290-299, 2015. https://doi.org/10.1016/j.polymdegradstab.2015.07.017 the NRDI Office under the auspices of the Ministry for Innovation and Technology. This paper was supported by the János Bolyai Research Scholarship of the Hungarian Academy of Sciences. The research was supported by the ÚNKP-20-5 New National Excellence Program of the Ministry for Innovation and Technology from the source of the National Research, Development and Innovation Fund. This publication was supported by the Italian-Hungarian bilateral agreement (grant number NKM73/2019) of the Hungarian Academy of Sciences.

[10] Ljungberg, N., Wesslén, B. "Preparation and Properties of Plasticized Poly(lactic acid) Films", Biomacromolecules, 6(3), pp. 1789-1796, 2005.

https://doi.org/10.1021/bm050098f

[11] Burgos, N., Martino, V. P., Jiménez, A. "Characterization and ageing study of poly(lactic acid) films plasticized with oligomeric lactic acid", Polymer Degradation and Stability, 98(2), pp. 651-658, 2013.

https://doi.org/10.1016/j.polymdegradstab.2012.11.009

[12] Irska, I., Paszkiewicz, S., Gorący, K., Linares, A., Ezquerra, T. A., Jędrzejewski, R., Rosłaniec, Z., Piesowicz, E. "Poly(butylene terephthalate)/polylactic acid based copolyesters and blends: miscibility-structure-property relationship", eXPRESS Polymer Letters, 14(1), pp. 26-47, 2020. https://doi.org/10.3144/expresspolymlett.2020.4

[13] Matta, A. K., Rao, R. U., Suman, K. N. S., Rambabu, V. "Preparation and Characterization of Biodegradable PLA/PCL Polymeric Blends", Procedia Materials Science, 6, pp. 1266-1270, 2014. https://doi.org/10.1016/j.mspro.2014.07.201

[14] Xu, S., Tahon, J. F., De-Waele, I., Stoclet, G., Gaucher, V. "Brittleto-ductile transition of PLA induced by macromolecular orientation", eXPRESS Polymer Letters, 14(11), pp. 1034-1047, 2020. https://doi.org/10.3144/expresspolymlett.2020.84

[15] Hajba, S., Tábi, T. "Cross Effect of Natural Rubber and Annealing on the Properties of Poly(Lactic Acid)", Periodica Polytechnica Mechanical Engineering, 63(4), pp. 270-277, 2019. https://doi.org/10.3311/PPme.12825

[16] Tábi, T. "The application of the synergistic effect between the crystal structure of poly(lactic acid) (PLA) and the presence of ethylene vinyl acetate copolymer (EVA) to produce highly ductile PLA/EVA blends", Journal of Thermal Analysis and Calorimetry, 138(2), pp. 1287-1297, 2019. https://doi.org/10.1007/s10973-019-08184-x

[17] Siakeng, R., Jawaid, M., Asim, M., Saba, N., Sanjay, M. R., Siengchin, S., Fouad, H. "Alkali treated coir/pineapple leaf fibres reinforced PLA hybrid composites: Evaluation of mechanical, morphological, thermal and physical properties", eXPRESS Polymer Letters, 14(8), pp. 717-730, 2020. https://doi.org/10.3144/expresspolymlett.2020.59 
[18] Kurniawan, D., Kim, B. S., Lee, H. Y., Lim, J. Y. "Atmospheric pressure glow discharge plasma polymerization for surface treatment on sized basalt fiber/polylactic acid composites", Composites Part B: Engineering, 43(3), pp. 1010-1014, 2012. https://doi.org/10.1016/j.compositesb.2011.11.007

[19] Tábi, T., Égerházi, A. Z., Tamás, P., Czigány, T., Kovács, J. G. "Investigation of injection moulded poly(lactic acid) reinforced with long basalt fibres", Composites Part A: Applied Science and Manufacturing, 64, pp. 99-106, 2014.

https://doi.org/10.1016/j.compositesa.2014.05.001

[20] Correia, M. S., Capela, C. A., Pouzada, A. S., Miranda, A. S. "Contributions to the modelling of ejection in injection moulding", In: International Conference on Polymers \& Moulds Innovations PMI 2007, Gent, Belgium, 2007.

[21] Jansen, K. M. B., Van Dijk, D. J., Husselman, M. H. "Effect of processing conditions on shrinkage in injection molding", Polymer Engineering and Science, 38(5), pp. 838-846, 1998. https://doi.org/10.1002/pen.10249

[22] Kovács, J. G. "Shrinkage alteration in the function of segregation of glass beads in injection molded PA6: Experimental analysis and modeling", Polymer Engineering and Science, 51(12), pp. 2517-2525, 2011.

https://doi.org/10.1002/pen.22025

[23] Postawa, P., Koszkul, J. "Change in injection moulded parts shrinkage and weight as a function of processing conditions", Journal of Materials Processing Technology, 162-163, pp. 109-115, 2005. https://doi.org/10.1016/j.jmatprotec.2005.02.241

[24] Suh, N. P., Mosleh, M., Howard, P. S. "Control of friction", Wear, 175(1-2), pp. 151-158, 1994. https://doi.org/10.1016/0043-1648(94)90178-3
[25] Temesi T., Czigány T. "Joining aluminium and poly(lactic acid) specimens by laser beam - a feasibility study", IOP Conference Series: Materials Science and Engineering, 903, Article number: 012046, 2020. https://doi.org/10.1088/1757-899X/903/1/012046

[26] Temesi, T., Czigány, T. "Integrated Structures from Dissimilar Materials: The Future Belongs to Aluminum-Polymer Joints", Advanced Engineering Materials, 22(8), Article number: 2000007, 2020.

https://doi.org/10.1002/adem.202000007

[27] Panin, C. V., Kornienko, L. A., Nguyen Suan, T., Ivanova, L. R., Poltaranin, M. A. "The Effect of Adding Calcium Stearate on Wear-resistance of Ultra-high Molecular Weight Polyethylene", Procedia Engineering, 113, pp. 490-498, 2015. https://doi.org/10.1016/j.proeng.2015.07.341

[28] International Organization for Standardization "ISO 527-2/1A Tensile Testing for Plastics", International Organization for Standardization, Geneva, Switzerland, 2012.

[29] Tábi, T., Kovács, J. G. "Fröccsöntött politejsav termékek vizsgálata" (Investigation of injection molded poly(lactic acid) products), Mủanyag és Gumi, 46, pp. 189-192, 2009. (in Hungarian)

[30] Battegazzore, D., Bocchini, S., Frache, A. "Crystallization kinetics of poly(lactic acid)-talc composites", eXPRESS Polymer Letters, 5(10), pp. 849-858, 2011. https://doi.org/10.3144/expresspolymlett.2011.84

[31] International Organization for Standardization "ISO 75-1:2020 Plastics - Determination of temperature of deflection under load - Part 1: General test method", International Organization for Standardization, Geneva, Switzerland, 2020. 